\title{
Serological and Nucleic Acid Based Detection of Brucellosis in Livestock Species and Molecular Characterization of Brucella melitensis Strains Isolated from Pakistan
}

\author{
Rashid Mahmood ${ }^{1,2}$, Usman Waheed ${ }^{2,3}$, Tayyaba Ali $^{2,4^{*}}$, Krishna K. Gopaul ${ }^{1}$, Amanda C. Dainty ${ }^{1}$, Jakub K. \\ Muchowski $^{1}$, Mark S. Koylass ${ }^{1}$, Simon D. Brew ${ }^{1}$, Lorraine L. Perrett ${ }^{1}$, Adrian M. Whatmore ${ }^{1}$ and Qaiser M. Khan $^{2}$ \\ ${ }^{1}$ FAO/WHO Collaborating Centre for Reference and Research on Brucellosis, Department of Bacteriology, Animal and Plant \\ Health Agency (APHA), Woodham Lane, New Haw, Addlestone, Surrey, United Kingdom \\ ${ }^{2}$ Soil and Environmental Biotechnology Division, National Institute for Biotechnology \& Genetic Engineering (NIBGE), \\ Jhang Road, Faisalabad, Pakistan \\ ${ }^{3}$ Department of Pathobiology, University of Veterinary and Animal Sciences, Lahore, Sub-campus Jhang, Pakistan \\ ${ }^{4}$ Department of Zoology, Government College University, Allama Iqbal Road, Faisalabad, Pakistan \\ *For correspondence: rashid.nibge@hotmail.com; ali.tayyaba@gmail.com
}

\begin{abstract}
This study aimed at molecular detection and characterization of Brucella spp from Pakistan. For this purpose, whole blood samples $(\mathrm{n}=167)$ were collected from different species of livestock and analysed at Animal and Plant Health Agency (APHA), United Kingdom. Samples were analysed employing Rose Bengal Test (RBT), Competitive Enzyme-linked immunosorbent assay (cELISA), PCR IS711 and culture examination. We found 1\% (2/167) samples positive for infection by culture, $4 \%$ (7/167) by RBT, 6\% (10/167) by cELISA and $21 \%(35 / 167)$ by PCR IS711. Results were found statistically significant using chi-square test ( $\mathrm{p}$-value <0.05). The blood culture positive bacterial isolations were further subjected to classical biotyping and molecular techniques for characterization and found as non-vaccine strains of Brucella melitensis. Molecular characterization using Multilocus Sequence Analysis (MLSA) and Variable Number of Tandem Repeat (VNTR) analysis demonstrated that although there was some similarity in the patterns generated, the isolations were distinct from each other. These isolates were not the part of geographically confined group but were representative of other B. melitensis strains found in the region stretching from southern Europe into South Asia. To our knowledge, this is the first report of molecular characterization of $B$. melitensis isolates from Pakistan. The molecular methods described in the present study will help to understand the disease dynamics and future brucellosis control in Pakistan. (C) 2016 Friends Science Publishers
\end{abstract}

Keywords: Brucellosis; Molecular Characterization; Brucella melitensis; MLSA; VNTR; Pakistan

\section{Introduction}

Brucellosis is a zoonosis of global socio-economic importance caused by Gram negative facultative intracellular bacteria of genus Brucella. The disease has been categorized as 'Multiple species disease' and noted in Notifiable Terrestrial and Aquatic Animal Diseases list of the World Organisation for Animal Health (OIE) (http://www.oie.int/animal-health-in-the-world/oie-listeddiseases-2014/). In developing countries, brucellosis is one of the most neglected endemic zoonotic diseases. Due to its consistent zoonotic nature attributable to human, livestock and wildlife, it ranks among the top 10 diseases of animals that are capable of infecting and putting multiple economic burdens on poor and improvised sections of human population (Perry, 2002). In livestock, brucellosis is the main cause of reproductive complications such as abortion and sterility whilst in human the disease can manifest itself in many ways including fever, general malaise and arthritis (Barbier et al., 2011). Genus Brucella is classified into different species based on phenotypic differences and host preferences. For host preference, B. melitensis is associated with sheep and goats, B. abortus with cattle, B. suis with pigs, B. ovis with sheep only, and B. canis with dogs (Verger et al., 1987). However, since 1994, several new Brucella species have been isolated from marine mammals (Foster et al., 2007) and voles (Scholz et al., 2008). More recently, several species of Brucella have been isolated from human (Scholz et al., 2010), non-human primates, foxes and frogs which determines the expanding nature of the genus (Schlabritz-Loutsevitch et al., 2009; Eisenberg et al., 2012; Hofer et al., 2012). It should, however, be noted that there are circumstances where Brucella species have been found to infect other host species in addition to their preferred host

To cite this paper: Mahmood, R., U. Waheed, T. Ali, K.K. Gopaul, A.C. Dainty, J.K. Muchowski, M.S. Koylass, S.D. Brew, L.L. Perrett, A.M. Whatmore and Q.M. Khan, 2016. Serological and nucleic acid based detection of brucellosis in livestock species and molecular characterization of Brucella melitensis strains isolated from Pakistan. Int. J. Agric. Biol., 18: 311-318 
such as B. abortus in sheep and goats (Elzer et al., 2002; Ocholi et al., 2005) or B. melitensis in cattle (Alvarez et al., 2011). Moreover, some of these species can be further subdivided into biovars based upon dye uptake (Farrel and Robertson, 1967), metabolic processes, susceptibility to phage (Corbel et al., 1988), hydrogen sulphide $\left(\mathrm{H}_{2} \mathrm{~S}\right)$ production, $\mathrm{CO}_{2}$ requirement and specific surface antigens (Alton et al., 1988).

Usually, brucellosis in animals can be diagnosed by clinical symptoms (abortions), culture from infected materials (blood, milk or afterbirth) and serology. In the case of serological tests, there are a number of different methodologies available for diagnosis including Rose Bengal Test (RBT), Serum Agglutination Test (SAT), Standard Tube Agglutination Test (STAT), Milk Ring Test (MRT) and Enzyme-linked immunosorbent Assay (ELISA) (Godfroid et al., 2010). However, more recently molecular tools, such as conventional and real-time PCR assays have been developed for both detection and characterization of Brucella (Yu and Nielsen, 2010). For conventional PCR, a number of targets such as bcsp31 (Baily et al., 1992) and multiple copy number insertion sequence IS711 (O'Leary et al., 2006) are available for the specific detection of Brucella. These assays can be applied directly for detection from clinical samples, without the need for setting up of cultures (Yu and Nielsen, 2010). Moreover, the use of molecular techniques like Multilocus Sequence Analysis (MLSA) and Variable Number of Tandem Repeat (VNTR) genotyping have allowed for more precise Brucella identification and brucellosis epidemiology (Whatmore, 2009). A number of recent isolates of Brucella have been identified using MLSA (Scholz et al., 2008, 2010; Schlabritz-Loutsevitch et al., 2009). Usefulness of VNTR in determining strain diversity in a population has been proven through literature (Cespedes et al., 2011) along with the determination of transmission between wild and domestic fauna (Abril et al., 2011) and possible zoonotic transmission (Gwida et al., 2012).

Pakistan is an agriculture based country and most of the population is involved in land cultivation and animal husbandry. A large number of human populations are exposed every day to a variety of animals and their excreta. This is particularly the case with rapid and continuous increasing dairy production units in the country and farmers/dairy men and their families are bound to work in the poor hygienic environments (Asif et al., 2014). The exact prevalence of brucellosis is not yet established in the country but it is believed to be endemic in nature depending on various factors like climatic conditions, host species, sex and age of the host animals. There are several published reports; however, no detailed data or proper reporting centres to outline the prevalence of brucellosis in man and animal is available (Nasir et al., 1999; Gul and Khan, 2007). Lack of proper diagnosis and extensive surveillance systems are the main reasons in documentation of exact picture of brucellosis in the country. Moreover, the use of sophisticated and robust techniques are still not fully validated. By developing and validating modern high throughput techniques, we can pave the way to address the disease control issues on scientific basis. In the present study, blood samples were collected from different regions; serum was separated and tested using a number of serological and molecular techniques. Phenotypic and molecular characterization of Brucella isolates using classical biotyping and molecular epidemiological tools are also provided. The data generated from this study will word as a guide to the future brucellosis studies and will be helpful in devising strategies for diagnosis, characterization, and control of brucellosis in livestock and human population in Pakistan.

\section{Materials and Methods}

\section{Sample Collection}

The blood samples $(n=167)$ were collected from selected areas of Hazara division, Peshawar and Charsada districts of Khyber Pakhtunkhwa (KPK) Province, Pakistan. Samples were collected from different farms/house hold animals having the history of reproductive problems in past. Five $\mathrm{mL}$ of blood from different species of livestock i.e. cattle, buffalo and goat was collected in duplicate vacutainers ${ }^{\circledR}$ (Beckton Dickinson, New Jersey, USA) for culture and serum separation. Serum was obtained by spinning whole blood samples for $15 \mathrm{~min}$ at $1790 \mathrm{x} \mathrm{g}$. The samples were then refrigerated and transported to Animal and Plant Health Agency (APHA), Surrey, United Kingdom where they were analysed at Department of Bacteriology, FAO/WHO Collaborating Centre for Reference and Research on Brucellosis. Gold standards for isolation and identification of Brucella and the diagnostic work were carried out according to OIE Manual of Standards for Diagnostic Tests and Vaccines (http://www.oie.int/manual-of-diagnostictests-and-vaccines-for-terrestrial-animals/).

\section{Serological Testing of Blood}

The serum samples were tested by Rose Bengal Test (RBT) and cELISA as described earlier (Alton et al., 1988; Stack et al., 1999) using the kits (APHA Weybridge, UK) according to manufacturer's instructions.

i. For RBT, $30 \mu \mathrm{L}$ of serum was taken on a white tile followed by the addition of equal measure of homogenous suspension of purified antigen. A visible clumping/agglutination were considered positive after thorough mixing for 3-4 min.

ii. The cELISA was performed using polystyrene plates coated with $B$. melitensis lipopolysaccaride antigen. Plates were labelled and the test serum samples were applied to the plate. Enzyme Labelled anti-Brucella antibodies (monoclonal antibody, MAb) were added followed by the addition of substrate and chromogen solution. The enzyme 
reacts with substrate and catalysed the reaction to detectable rate by the transforming the colourless chromogen into pigmented compound in those wells that had bound the enzyme labelled antibodies to the antigenic sites on the plate. Detectable quantities of bound enzyme labelled antibodies were not available in those wells which were exposed to positive serum as the antibodies from the positive sample bound to the antigenic sites in the wells preventing the enzyme labelled antibodies from binding. The optical density (OD) was read at $450 \mathrm{~nm}$ and the \% OD of $50 \%$ was used as basic criteria for the interpretation of results.

\section{Isolation and Identification of Brucella through Conventional Biotyping Techniques}

For isolation, $1 \mathrm{~mL}$ of blood was added to $10 \mathrm{~mL}$ of Brodie and Sinton broths (Bordie, and Sinton, 1975) followed by sub-culturing on Serum Dextrose Agar (SDA) (Jones and Morgan, 1958) and Farrell's media plates (Farrell and Robertson, 1972). Suspected isolates were subjected to various biochemical tests for typing which include serotyping, urease production, $\mathrm{H}_{2} \mathrm{~S}$ production, dye-plate inhibition, $\mathrm{CO}_{2}$ dependency, and phage typing. The World Animal Health (OIE) recognised methodology and APHA Standard Operating Procedures (SOPs) were strictly followed.

\section{Extraction and Testing for Presence of Brucella DNA from Serum Samples}

To test directly from clinical material, DNA was extracted from $200 \mu \mathrm{L}$ of serum using the DNeasy Blood and Tissue kit (Qiagen, Hilden, Germany) following the kit protocol. Conventional PCR based on the Brucella spp. specific target IS711 (O'Leary et al., 2006) was performed for the detection of Brucella. The PCR reaction mixture was prepared with a final volume of $25 \mu \mathrm{L}$. FastStart 1x PCR buffer with $\mathrm{MgCl}_{2}$ (Roche), $0.4 \mathrm{mM}$ dNTPs, $800 \mathrm{nM}$ of both forward and reverse primers, 1 unit FastStart Taq DNA polymerase (Roche) with $5 \mu \mathrm{L}$ template DNA (from DNeasy extraction). The following oligonucleotide forward (5'GACGAACGGAATTTTTCCAATCCC-3') and reverse (5'-TGCCGATCACTTAAGGGCCTTCAT-3') primers were used during the reaction. Thermocycler parameters used were as follows: pre-incubation at $94^{\circ} \mathrm{C}$ for $5 \mathrm{~min}, 40$ cycles of $94^{\circ} \mathrm{C}$ for $30 \mathrm{sec}$ for heating, $63^{\circ} \mathrm{C}$ for $30 \mathrm{sec}$ for annealing and $72^{\circ} \mathrm{C}$ for $1 \mathrm{~min}$ for extension and final extension step of $72^{\circ} \mathrm{C}$ for $5 \mathrm{~min}$. We spiked an aliquot of each sample with $1 \mu \mathrm{L}$ of a $1 \mathrm{ngmL}^{-1}$ dilution of $B$. abortus (strain 544) genomic DNA obtained through phenol chloroform extraction (Sambrook et al., 1989) to check for possible inhibition or false negatives through PCR. The products of amplification were visualised using a $2 \%$ agarose gel and a size marker of $1 \mathrm{~kb}$, with a fragment size of $498 \mathrm{bp}$ corresponding to the desired IS711 target (O'Leary et al., 2006). Each sample was tested in duplicate and only those that generated a product of the correct size on both occasions were identified as Brucella positive.

\section{Molecular Characterization of Bacterial Isolations}

Molecular characterization was carried out for classification of Brucella into species and biovars. In brief, genomic DNA was extracted from field isolates which grew on blood culture through procedures as explained earlier by Whatmore et al. (2005). Based on single nucleotide polymorphism (SNP) identified by Whatmore et al. (2007), species identification of field isolates and determination of possible vaccine markers were undertaken using previously described multiple outcome real-time PCR assays (Goupal et al., 2008, 2010). These competition assays were set up in final reaction volume of $12.5 \mu \mathrm{L}$ containing $6.25 \mu \mathrm{L}$ TaqMan genotyping mix (Applied Biosystems, Warrington, United Kingdom) using Agilent MX3005p platform (Agilent, La Jolla, CA) with working concentrations of primers, probes and cycling conditions as mentioned in above citation. MxPro software provided with Mx3005p was used for analysis of results.

Multilocus Sequence Analysis (MLSA) was performed using nine unique genome sequences amplified through PCR according to the procedure illustrated by Whatmore et al. (2007). The amplified PCR products were purified using the QIA quick 96 PCR purification kit (QIAGEN, cat. no. 28183) followed by sequencing using Big Dye terminator cycle sequencing kit (version 3.1, Applied Biosystems) according to manufacturer's guidelines. Sequenced data was edited by using DNA Star ${ }^{\circledR}$ Lasergene 8 software and Phylogenetic analysis was performed using MEGA 6.0 (Tamura et al., 2013). For VNTR analysis, an MLVA-16 approach as used by Al Dahouk et al. (2007) was adopted for typing and species identification of Brucella. Fragment sizes were determined using an ABI3130 x 1 sequencer (Applied Biosystems, Warrington, UK) as per manufacturer's instructions. Fragment sizes were imported into GeneMapper ${ }^{\circledR}$ v3.7 software (Applied Biosystems, Warrington, UK) and VNTR allele calls (number of DNA tandem repeats) generated. VNTR allele calls were analysed in Bionumerics v6.6 (Applied Maths) as character data.

\section{Analysis of the Diagnostic Testing}

The diagnostic data were statistically analysed with chisquare test $\left(\chi^{2}\right)$ (Steel et al., 1997) using GraphPad Prism, version 6.05 (La Jolla, CA USA), (www.graphpad.com). Pvalue $<0.05$ was considered statistically significant.

\section{Results}

\section{Serological, Molecular and Culture Diagnosis of Samples}

Serological testing of the 167 serum samples found 7 (4\%) samples positive by RBT and $10(6 \%)$ by cELISA for presence of antibodies against Brucella whereas molecular testing using IS711 PCR and blood culture identified 35 
$(21 \%)$ and $2(1 \%)$ positives, respectively $\left(\chi^{2}=52.30, \mathrm{P}<0.05\right)$ (Table 1). Species-wise occurrence of disease was found higher in goats as compared to bovine (cattle and buffalo) (Table 1). Results from different methods used for brucellosis diagnosis are plotted in Venn diagram for comparative analysis showing $2(1 \%)$ samples out of 167 as positive by all serological, molecular and culture detection methods remarking the discrepancies of different diagnostic procedures used during the study (Fig. 1).

\section{Culture and Classical Biotyping}

Traditional microbial tests phenotypically identified the characteristics of Brucella positive in two blood cultures (Table 1) and were referred to as S26 and S27. These field isolates grew on Serum Dextrose Agar (SDA) showed urease activity but did not produce $\mathrm{H}_{2} \mathrm{~S}$. Culture plates containing Thionin and Basic Fuchsin dyes did not inhibit the growth of Brucella. Both isolates showed better growth on $\mathrm{CO}_{2}$ dependency plates without any supplementary $\mathrm{CO}_{2}$ presence (Table 2). The isolates were subjected to agglutination tests for their predominant agglutinogen (A or $\mathrm{M}$, indicating $B$. abortus and $B$. melitensis antigens respectively) with mono-specific $\mathrm{A}$ and $\mathrm{M}$ antisera. They were agglutinated with $\mathrm{M}$ mono-specific serum only. Phage typing showed the Partial Lysis (PL) with Berkeley (Bk2) and Izatnagar (Iz) (Table 2). Based on these phenotypic characteristics and phage typing, S26 and S27 field isolates were identified as B. melitensis biovar 1 .

\section{Molecular Analysis of Bacterial Isolates}

The samples identified and characterized as B. melitensis biovar 1 through standard and classical biotyping techniques were further subjected to molecular characterization. Using single nucleotide polymorphism (SNP) based multiple outcome real-time PCR and vaccine strain identification assays, it was possible to confirm the identity of the two Brucella isolates as non-vaccine B. melitensis strains (Fig. $2 \mathrm{a}$ and $\mathrm{b}$ ). The 9-loci MLSA profiles generated by the isolates were identical and comparable with other Brucella MLSA profiles held at the APHA internal database. It was determined that both profiles fall in sequence type (ST) 8 , which is a type associated with B. melitensis (Fig. 3). Within this ST, there are strains from each of the three accepted $B$. melitensis biovars (including the $B$. melitensis biovar 2 strain 63/9). There were a number of strains associated with geographical areas like India, Middle East and Southern Europe.

Subsequently MLVA-16 was performed on the isolates, which showed that there were similarities at a number of VNTR loci, but they were unique to each other based on differences at two loci (Table 3). Using a weighted analysis, the isolates were compared with $108 \mathrm{~B}$. melitensis profiles from a global database held at the Institut Pasteur, Paris (http://mlva.u-psud.fr/brucella/) using

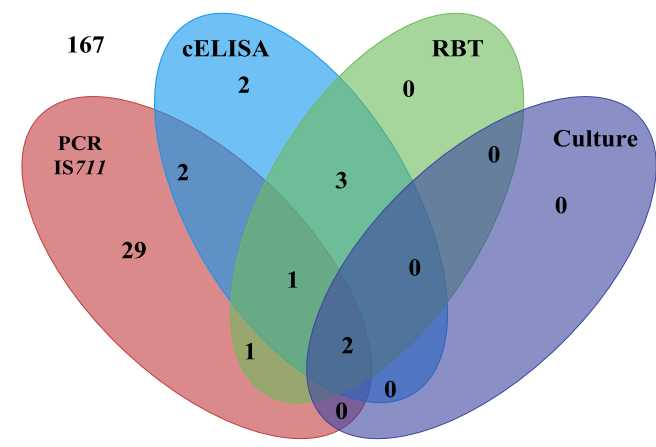

Fig. 1: Venn diagram showing a summary of serological (RBT, cELISA), molecular and cultural testing results of animal samples $(n=167)$ illustrationg the number of positive samples with single and multiple tests

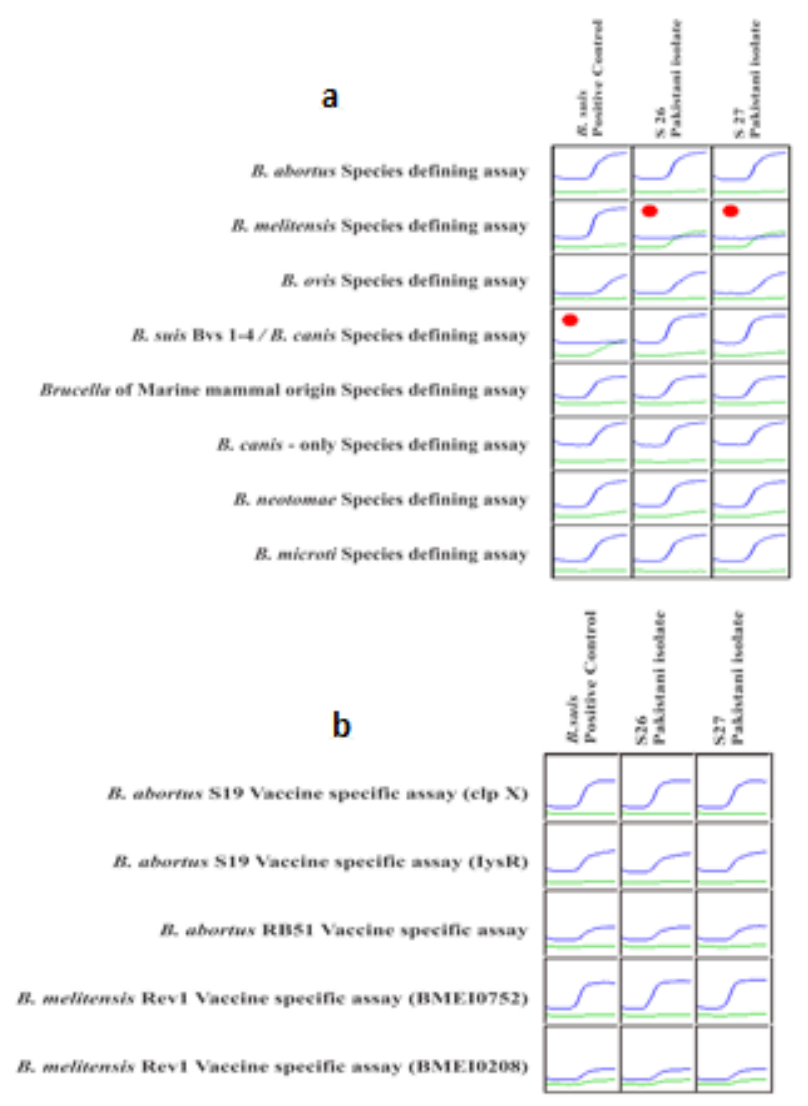

Fig. 2a, b: Results of real time PCR identification of caprine isolates based on species (a) and vaccine (b) specific SNPs. From these tests both S26 and S27 isolates were positively identified as non-vaccine $B$. melitensis

the Bionumerics Version 6.6 software (Applied Maths, Sint-Martens-Latem, Belgium) for further characterization. The placement of these strains in the current global scheme showed that these strains grouped with $B$. melitensis isolates 
Table 1: Overall and species-wise results of different methods used for brucellosis diagnosis from blood and serum samples

\begin{tabular}{|c|c|c|c|c|c|}
\hline \multirow[t]{2}{*}{ Animal Species } & \multirow[t]{2}{*}{ Number of samples } & \multicolumn{4}{|c|}{ Positive samples detected } \\
\hline & & RBT & cELISA & IS711 PCR & Culture \\
\hline Cattle & 92 & $2(2 \%)$ & $2(2 \%)$ & $13(14 \%)$ & 0 \\
\hline Buffalo & 45 & 0 & $1(2 \%)$ & $11(24 \%)$ & 0 \\
\hline Goat & 30 & $5(16 \%)$ & $7(23 \%)$ & $11(36 \%)$ & $2(6 \%)$ \\
\hline${ }^{*}$ Total & 167 & $7(4 \%)$ & $10(6 \%)$ & $35(21 \%)$ & $2(1 \%)$ \\
\hline
\end{tabular}

${ }^{*}$ The differences among IS711 PCR assay results, serology and culture were found to be statistically significant $\left(\chi^{2}=52.30 ; p<0.05\right)$

Table 2: Biochemical, agglutination and Phage lysis test results of bacterial isolations

\begin{tabular}{|c|c|c|c|c|c|c|c|c|c|c|c|c|c|c|}
\hline \multirow[t]{2}{*}{$\overline{\text { Sample }}$} & \multicolumn{5}{|c|}{ Growth Characteristics } & \multicolumn{2}{|c|}{ Monospecific Sera } & \multicolumn{6}{|c|}{ Phages } & \multirow[t]{2}{*}{ Interpretation } \\
\hline & Urea & $\mathrm{H}_{2} \mathrm{~S}$ & $\mathrm{CO}_{2}$ & $\mathrm{BF}$ & $\mathrm{TH}$ & $\mathrm{A}$ & $\mathrm{M}$ & $\mathrm{Wb}$ & $\mathrm{Tb}$ & BK & $\mathrm{Fi}$ & $\mathrm{Iz}$ & $\mathrm{R} / \mathrm{C}$ & \\
\hline S26 & ++ & - & - & + & + & - & + & NL & NL & PL & NL & PL & NL & B. melitensis 1 \\
\hline S27 & ++ & - & - & + & + & - & + & NL & NL & PL & NL & PL & NL & B. melitensis 1 \\
\hline \multicolumn{8}{|c|}{$\mathrm{BF}=$ Basic fuchsin at $20 \mu \mathrm{l} / \mathrm{ml}(1 / 50,000 \mathrm{w} / \mathrm{v})$} & \multicolumn{7}{|c|}{ Phages : Wb: Weybourne } \\
\hline \multicolumn{8}{|c|}{$\mathrm{TH}=$ Thionin at $20 \mu \mathrm{l} / \mathrm{ml}(1 / 50,000 \mathrm{w} / \mathrm{v})$} & \multicolumn{7}{|c|}{ Tb: Tbilisi } \\
\hline \multicolumn{8}{|c|}{$\mathrm{CL}=\mathrm{Confluent}$ Lysis } & \multicolumn{7}{|c|}{ Bk: Berkeley } \\
\hline \multicolumn{8}{|c|}{$\mathrm{PL}=$ Partial lysis } & \multirow{2}{*}{\multicolumn{7}{|c|}{ Fi: Firenze }} \\
\hline \multicolumn{6}{|c|}{$\mathrm{NL}=$ No lysis } & & & & & \multicolumn{4}{|c|}{ Iz: Izatnagar } & \\
\hline
\end{tabular}

Table 3: MLVA16 profiles for isolated strains showing that both strains are similar but have differences in two loci (highlighted)

\begin{tabular}{|c|c|c|c|c|c|c|c|c|c|c|c|c|c|c|c|}
\hline Sample & Bruce06 & VNTR26 & Bruce11 & Bruce12 & Bruce42 & Bruce43 & VNTR7 & VNTR24 & VNTR17 & Bruce19 & Bruce21 & HP6 & VNTR5a HP8 & VNTR2 & $\mathrm{HP} 2$ \\
\hline S26 & 1 & 5 & 3 & 13 & 2 & 2 & 3 & 2 & 4 & 40 & 8 & 5 & 4 & 2 & 6 \\
\hline S27 & 1 & 5 & 3 & 13 & 2 & 2 & 3 & 2 & 4 & 40 & 8 & 5 & 4 & 7 & 6 \\
\hline
\end{tabular}

from the "East Mediterranean" group (Fig. 4).

\section{Discussion}

Comparison of Culture, Serological and Molecular Diagnostic Methods

There are a number of published studies regarding prevalence of brucellosis in different areas of Pakistan, in livestock (Nasir et al., 1999), human population (Mukhtar and Kokab, 2008; Mukhtar, 2010; Ali et al., 2013) and the food chain (Hassan et al., 2010; Shafee et al., 2011). However, it should be noted that the work by Hassan et al. (2010) described the isolation of Brucella organisms by culture, which was the part of a wider study into the microbial contamination of meat. In this way the emphasis on many of these previous studies has been the diagnosis of infection through serological response and not on the direct detection of the causative agent through either culture or molecular methods.

Recently, Ali et al. (2014) described the isolation of 30 B. abortus strains in aborted foeti, vaginal swabs and milk samples collected from bovids that had either aborted or produced antibodies to Brucella in milk. Strains were confirmed as B. abortus by cultural and molecular methods (Bricker and Halling, 1994). A more holistic approach was adopted by Akhtar et al. (2010) who used a combination of serological, culture and molecular methods to screen milk

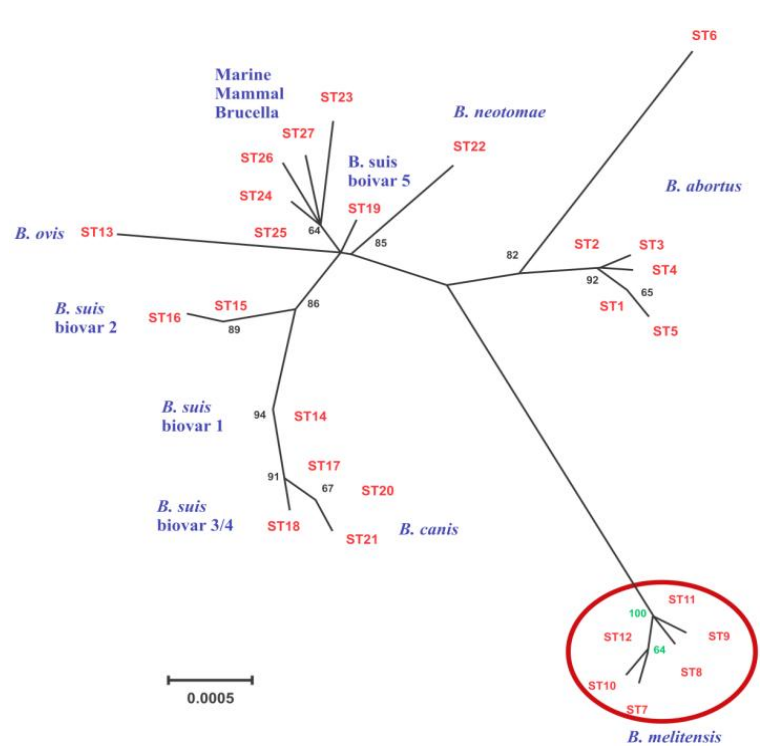

Fig. 3: This figure was adapted from Whatmore et al. (2007) and showed the placement of ST8 within the three main groups associated with $B$. melitensis (circled)

and serum samples from 100 cattle and 100 buffalo. The same PCR test was used to determine the presence of pathogens in milk and serum samples (O'Leary et al., 2006) with results being compared with culture outcomes.

It was established that PCR testing of sera and milk 
generated more positive results than serology. It was suggested that PCR of serum samples along with serological testing could be used as rapid screening method for bovine brucellosis (Akhtar et al., 2010). These observations are similar to those seen in the present study, where PCR identified 35 positive samples, whereas RBT and cELISA detected 7 and 10 positive, respectively. However, there was poor correlation between the results of PCR and serology. In present study, 29/35 PCR positive samples were tested as negative for brucellosis by serology. Similarly, 3/7 and 5/10 serological positives by RBT and cELISA, respectively, were PCR negative (Fig. 1). This is in contrast to another study comparing molecular and serological diagnosis of brucellosis in Malaysian goats where it was found that 70/288 goats tested were positive by complement fixation test (CFT) and conventional PCR, whereas 200/288 were negative by both of these tests (AlGaradia et al., 2011). This observation is confusing as it has been shown that cELISA is a robust serological test that can be used to detect samples unsuitable for CFT (Stack et al., 1999) and is also as sensitive as CFT in goats (Perret et al., 2010). With this and the PCR results in mind, it was expected to see more serological positives than seen in this test. However, the fact that both culture confirmed samples in present study were also positive by RBT, cELISA and PCR, which at least showed that using a combination of diagnostic methods was as good as culture test.

\section{Molecular Characterization of $\boldsymbol{B}$. melitensis Isolates}

This study, to our knowledge, is the first one to describe the molecular characterization of $B$. melitensis strains isolated from Pakistan using MLSA profiles and VNTR loci. Although host specificity in Brucella is not a rigid determinant of species, in the current study, the isolates were identified by both classical and molecular methods as $B$. melitensis; the species associated most strongly with caprine brucellosis (Elzer et al., 2002) and considered the most significant human pathogen within the genus Brucella (Colmenero et al., 1996). Regarding Brucella identification, it should be noted that classical methods were performed in three days with specialized handling facilities. On contrary, the molecular identification was performed from a crude extraction in a general laboratory setting within $3 \mathrm{~h}$. To determine if the strain is a vaccine (Rev1) by culture, drug resistance profiles for streptomycin and penicillin would require an additional 3 days, whereas the molecular methods can provide the same level of information within $3 \mathrm{~h}$ of the preparation of a crude extraction. After preliminary identification of Brucella, the techniques of MLSA and VNTR (MLVA-16) were carried out to further characterize the isolates and to place them in a global Brucella context using nucleotide databases. It should be noted that the MLVA profiles of the isolates were quite distant from the only other available Pakistani $B$. melitensis isolate which was obtained from a human (Al Dahouk et al.,

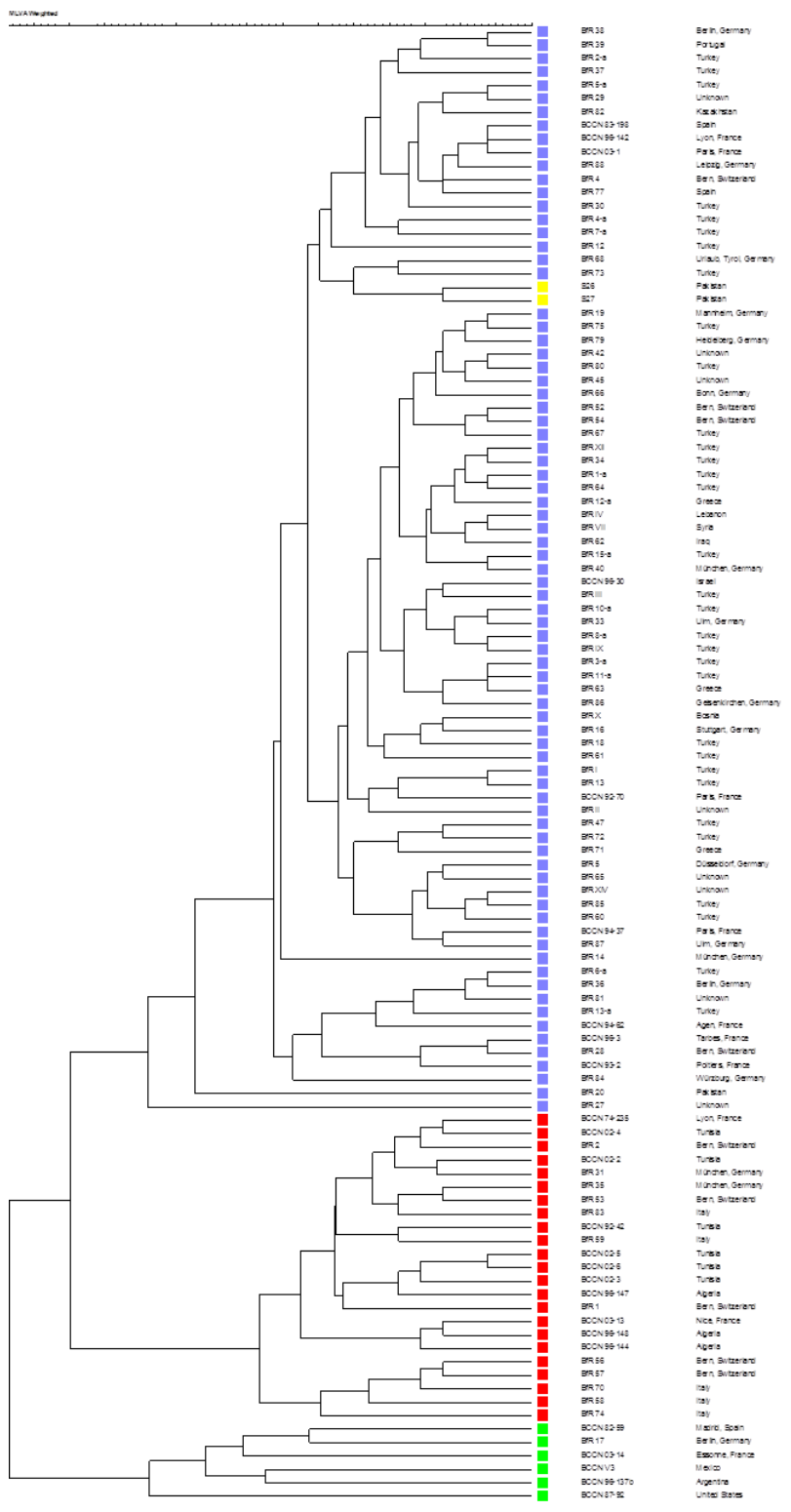

Fig. 4: Weighted dendrogram of isolates taken from $\mathrm{Al}$ Dahouk et al. (2007) with isolates of present study (in yellow) to determine MLVA16 "grouping" within $B$. melitensis. The groups are East Mediterranean (blue), West Mediterranean (Red) and American (Green). The isolates of present study belong to the East Mediterranean group

2007) suggesting the circulation of diverse genotypes. Further, the results from both molecular methods suggest that these Pakistani isolates were not part of a geographically confined group but were representative of other B. melitensis strains found in a region stretching from southern Europe into South Asia. The isolation of $B$. melitensis from caprines in Pakistan along with previous $B$. abortus in bovids (Ali et al., 2014) suggests that there is Brucella strain diversity within Pakistan. 


\section{Conclusion}

In conclusion, classical biotyping techniques followed by molecular tools provide a handful mechanism to characterize the genus Brucella and to understand the genetic diversity of organism. The IS711 PCR was found to be more sensitive and accurate method of identification. It was found that serum could be used as dependable and safer clinical sample for serological and molecular diagnosis than whole blood or other foetal tissue posing less hazards to laboratory workers. It is also observed that a battery of tests containing more than one test should be followed for getting consensus results. However, more systematic studies will be required to establish the prevalence of brucellosis and the significance of each species in the livestock of Pakistan. Having these data will allow decision makers to make informed choices for future brucellosis control measures.

\section{Acknowledgements}

The authors would like to acknowledge the technical assistance provided by Mr. Andrew Taylor and Ms. EmmaJane Dale for the serological work and Mr. Steven Shankster and Ms. Pauline Groussaud for their work in the initial VNTR analysis of strains. This work was funded by Higher Education Commission of Pakistan (HEC) and the Department of Environment, Food and Rural Affairs (Defra), United Kingdom as part of ROAME projects SE0311 and SE0313.

\section{References}

Abril, C., A. Thomann, I. Brodard, N. Wu, M.P. Ryser-Degiorgis, J. Frey and G. Overesch, 2011. A novel isolation method of Brucella species and molecular tracking of Brucella suis biovar 2 in domestic and wild animals. Vet. Microbiol., 150: 405-410

Akhtar, R., Z.I. Chaudhry, A.R. Shakoori, M. Ahmad and A. Aslam, 2010. Comparative efficacy of conventional diagnostic methods and evaluation of polymerase chain reaction for the diagnosis of bovine brucellosis. Vet. World, 3: 53-56

Al Dahouk, S., P.L. Fleche, K. Nockler, I. Jacques, M. Grayon, H.C. Scholz, H. Tomaso, G. Vergnaud and H. Neubauer, 2007. Evaluation of Brucella MLVA typing for human brucellosis. J. Microbiol. Methods., 69: 137-145

Al-Garadia, M.A., S. Khairani-Bejo, Z. Zunita and A.R. Omar, 2011. Detection of Brucella melitensis in blood samples collected from goats. J. Amin. Vet. Adv., 10: 1437-1444

Ali, S., Q. Ali, F. Melzer, I. Khan, S. Akhter, H. Neubauer and S.M. Jamal, 2014. Isolation and Identification of bovine Brucella isolates from Pakistan by biochemical tests and PCR. Trop. Anim. Health Prod., 46: 73-78

Ali, S., Q. Ali, H. Neubauer, F. Melzer, M. Elschner, I. Khan, E.N. Abatih, N. Ullah, M. Irfan and S. Akhtar, 2013. Sero prevalence and risk factors associated with brucellosis as a professional hazard in Pakistan. Food Borne Pathog. Dis., 10: 500-505

Alton, G.G., L.M. Jones, R.D. Angus and J.M. Verger, 1988. Techniques for the Brucellosis Laboratory. Institut National de la recherché Agronomique (INRA), Cedex, France

Alvarez, J., J.L. Saez, N. Garcia, C. Serrat, M. Perez-Sancho, S. Gonzalez, M.J. Ortega, J. Gou, L. Carbajo, F. Garrido, J. Goyache and L. Dominguez, 2011. Management of an outbreak of brucellosis due to B. melitensis in dairy cattle in Spain. Res. Vet. Sci., 90: 208-211
Asif, M., U. Waheed, M. Farroq, T. Ali and Q.M. Khan, 2014. Frequency of Brucellosis in high risk human groups in Pakistan detected through polymerase chain reaction and its comparison with conventional slide agglutination test. Int. J. Agric. Biol., 16: 986-990

Baily, G.G., J.B. Krahn, B.S. Drasar and N.G. Stoker, 1992. Detection of Brucella melitensis and Brucella abortus by DNA amplification. $J$. Trop. Med. Hyg., 95: 271-275

Barbier, T., C. Nicolas and J.J. Letesson, 2011. Brucella adaptation and survival at the crossroad of metabolism and virulence. FEBS Lett., 585: 2929-2934

Bricker, B.J. and S.M. Halling, 1994. Differentiation of Brucella abortus bv. 1, 2 and 4, Brucella melitensis, Brucella ovis, and Brucella suis bv. 1 by PCR. J. Clin. Microbiol., 32: 2660-2666

Bordie, J. and G.P. Sinton, 1975. Fluid and solid media for isolation of Brucella abortus. J. Hyg. (Lond)., 74: 359-367

Cespedes, S., P. Salgado, P. Valenzuela, R. Vidal and A.A. Onate, 2011. Characterization of genomic island 3 and genetic variability of Chilean field strains of Brucella abortus. J. Clin. Microbiol., 49: 2461-2469

Colmenero, J.D., J.M. Reguera, F. Martos, D. Sanchez-de- Mora, M. Delgado, M. Causse, A. Martin-Farfan and C. Juarez, 1996. Complications associated with Brucella melitensis infection: a study of 530 cases. Med. (Baltimore), 75: 195-211

Corbel, M.J., F. Tolari and V.K. Yadava, 1988. Characterisation of a new phage lytic for both smooth and non-smooth Brucella species. Res. Vet. Sci., 44: 45-49

Eisenberg, T., H.P. Hamann, U. Kaim, K. Schlez, H. Seeger, N. Schauerte, F. Melzer, H. Tomaso, H.C. Scholz, M.S. Koylass, A.M. Whatmore and M. Zschock, 2012. Isolation of potentially novel Brucella spp. from frogs. Appl. Environ. Microbiol., 78: 3753-3755

Elzer, P.H., S.D. Hagius, D.S. Davis, V.G. DelVecchio and F.M. Enright, 2002. Characterization of the caprine model for ruminant brucellosis. Vet. Microbiol., 90: 425-431

Farrell, I.D. and L. Robertson, 1967. The sensitivity of the biotypes of Brucella abortus to three antibiotics used in selective media, and the description of a new biotype. J. Hyp. (London), 65: 165-172

Farrell, I.D. and L. Robertson, 1972. A comparison of various selective media, including a new selective medium for the isolation of brucellae from milk. J. Appl. Bacteriol., 35: 625-630

Foster, G., B.S. Osterman, J. Godfroid, I. Jacques and A. Cloeckaert, 2007. Brucella ceti sp. nov. and Brucella Pinnipedialis sp. nov. for Brucella strains with cetaceans and seals as their preferred hosts. Int. J. Syst. Evol. Microbiol., 57: 2688-2693

Godfroid, J., K. Nielsen and C. Saegerman, 2010. Diagnosis of brucellosis in livestock and wildlife. Croat. Med. J., 51: 296-305

Goupal, K.K., M.S. Koylas, C.J. Smith and A.M. Whatmore, 2008. Rapid identification of Brucella isolates to the species level by real time PCR based single nucleotide polymorphism (SNP) analysis. BMC Microbiol., 8: 86

Goupal, K.K., J. Sells, B.J. Bricker, O.R. Crasta and A.M. Whatmore, 2010. Rapid and reliable single nucleotide polymorphism-based differentiation of Brucella live vaccine strains from field strains. $J$. Clin. Micorbiol., 48: 1461-1464

Gul, S.T. and A. Khan, 2007. Epidemiology and epizootology of brucellosis: A review. Pak Vet. J., 27: 145-151

Gwida, M., H. Neubauer, Z. Ilhan, G. Schmoock, F. Melzer, K. Nockler, P. Janczyk, H. Tomaso, U. Rosler and S. Al Dahouk, 2012. Crossborder molecular tracing of brucellosis in Europe. Comp. Immunol. Microbiol. Infect. Dis., 35: 181-185

Hassan, A.N., A. Farooqi, A. Khan, A.Y. Khan and S.U. Kazmi, 2010. Microbial contamination of raw meat and its environment in retail shops in Karachi, Pakistan. J. Infect. Dev. Ctries., 4: 382-388

Hofer, E., S. Revilla-Fernandez, S. Al Dahouk, J.M. Riehm, K. Nockler, M.S. Zygmunt, A. Cloeckaert, H. Tomaso and H.C. Scholz, 2012. A potential novel Brucella species isolated from mandibular lymph nodes of red foxes in Austria. Vet. Microbiol., 155: 93-99

Jones, L.M. and W.J.B. Morgan, 1958. A preliminary report on a selective medium for the culture of Brucella, including fastidious types. Bull. World Health Organ., 19: 200-203

Mukhtar, F. and F. Kokab, 2008. Brucella serology in abattoir workers. J. Ayub Med. Coll., 20: 57-61 
Mukhtar, F., 2010. Brucellosis in a high risk occupational group: seroprevalence and analysis of risk factors. JPMA J. Pak. Med. Assoc., 60: 1031-1034

Nasir, A.A., M.A. Shah and M. Rashid, 1999. Current status of Brucellosis in Cattle at Various Government Livestock Farms in Punjab. Int. J. Agric. Biol., 1: 337-338

Ocholi, R.A., J.K.P. Kwaga, I. Ajogi and J.O.O. Bale, 2005. Abortion due to Brucella abortus in sheep in Nigeria. Rev. Sci. Tech. Int. Off. Epizoot., 24: 973-979

O'Leary, S., M. Sheahan and T. Sweeney, 2006. Brucella abortus detection by PCR assay in blood, milk and lymph tissue of serologically positive cows. Res. Vet. Sci., 81: 170-176

Perrett, L.L., J.A. McGiven, S.D. Brew and J.A. Stack, 2010. Evaluation of competitive ELISA for detection of antibodies to Brucella infection in domestic animals. Croat. Med. J., 51: 314-319

Perry, B.D., 2002. Ch.7-Animal Disease Impact on Poor: Study Results, pp: 67-78. Investing in Animal Research to Alleviate Poverty. International Livestock Research Institute, Nairobi, Kenya

Sambrook, J., E.F. Fritsch and T. Maniatis, 1989. Molecular Cloning, a Laboratory Manual, $3^{\text {rd }}$ edition. Cold Spring Harbour Laboratory Press, New York, USA

Schlabritz-Loutsevitch, N.E., A.M. Whatmore, C.R. Quance, M.S. Koylas, L.B. Cummins, E.J. Dick Jr, C.L. Snider, D. Cappelli, J.L. Ebersole, P.W. Nathanielsz and G.B. Hubbard, 2009. A novel Brucella isolate in association with two cases of stillbirth in non-human primates-first report. J. Med. Primatol., 38: 70-73

Scholz, H.C., Z. Hubalek, I. Sedlacek, G. Vergnaud, H. Tomaso, S. Al Dahouk, F. Melzer, P. Kampfer, H. Neubauer, A. Cloeckaert, M. Maquart, M.S. Zygmunt, A.M. Whatmore, E. Falsen, P. Bahn, C. Gollner, M. Pfeffer, B. Hubber, H.J. Busse and K. Nockler, 2008. Brucella microti sp. nov., isolated from the common vole Microtus arvalis. Int. J. Syst. Evol. Microbiol., 58: 375-382
Scholz, H.C., K. Nockler, C. Gollner, P. Bahn, G. Vergnaud, H. Tomaso, S. Al Dahouk, P. Kampfer, A. Cloeckaert, M. Maquart, M.S. Zygmunt, A.M. Whatmore, M. Pfeffer, B. Huber, H.J. Busse and B.K. De, 2010. Brucella inopinata sp. nov., isolated from a breast implant infection. Int. J. Syst. Evol. Microbiol., 60: 801-808

Shafee, M., M. Rabbani, A.A. Sheikh, M.D. Ahmad and A. Razzaq, 2011. Prevalence of bovine brucellosis in organized dairy farms, using milk elisa, in Quetta City, Baluchistan. Vet. Med. Int., Article ID 358950

Stack, J.A., L.L. Perrett, S.D. Brew and A.P. MacMillan, 1999. Competitive ELISA for bovine brucellosis suitable for testing poor quality samples. Vet. Rec., 145: 735-736

Steel, R.G.D., J.H. Torriee and D.A. Dickey, 1997. Principles and Procedures of Statistics: A Biometrical Approach, $3^{\text {rd }}$ ed. McGrawHill Book Company, New York, USA

Tamura, K., G. Stecher, D. Peterson, A. Filipski and S. Kumar, 2013. MEGA6: molecular evolutionary genetics analysis version 6.0. Mol. Biol. Evol., 30: 2725-2729

Verger, J.M., F. Grimont P.A. Grimont and M. Grayon, 1987. Taxonomy of the genus Brucella. Ann. Inst. Pasteur. Microbiol., 138: 235-238

Whatmore, A.M., T.J. Murphy, S. Shankster, E. Young, S.J. Cutler and A.P. Macmillan, 2005. Use of amplified fragment length polymorphism to identify and type Brucella isolates of medical and veterinary interest. J. Clin. Microbiol., 43: 761-769

Whatmore, A.M., L.L. Perrett and A.P. Macmillan, 2007. Characterisation of the genetic diversity of Brucella by multilocus sequencing. BMC Microbiol., 7: 34

Whatmore, A.M., 2009. Current understanding of the genetic diversity of Brucella, an expanding genus of zoonotic pathogens. Infect. Genet Evol., 9: 1168-1184

Yu, W.L. and K. Nielsen, 2010. Review of detection of Brucella spp. by polymerase chain reaction. Croat. Med. J., 51: 306-313

(Received 27 March 2015; Accepted 07 August 2015) 